Case Reports in
Gastroenterology
Case Rep Gastroenterol 2020;14:346-353

DOI: 10.1159/000508435

Published online: July 22, 2020 (c) 2020 The Author(s)

Published by S. Karger AG, Basel www.karger.com/crg

This article is licensed under the Creative Commons Attribution-NonCommercial 4.0 International License (CC BY-NC) (http://www.karger.com/Services/OpenAccessLicense).

Usage and distribution for commercial purposes requires written permission.

\title{
Intestinal Obstruction due to Acute Appendicitis
}

\author{
Pham Hong Duc ${ }^{a} \quad$ Ngo Minh Xuan ${ }^{b} \quad$ Nguyen Huu Thuyet ${ }^{a}$ \\ Huynh Quang Huy \\ aDepartment of Radiology, Ha Noi Medical University, Ha Noi, Vietnam; 'bepartment of \\ Radiology, Pham Ngoc Thach University of Medicine, Ho Chi Minh City, Vietnam
}

\section{Keywords}

Intestine $\cdot$ Obstruction · Acute appendicitis

\begin{abstract}
Acute appendicitis has been proven to be a usual cause of mechanical small bowel obstruction since 1901, but there has been very little specific research on this subject. It usually occurs as an effect of adhesion because of periappendicular inflammation. Although previous studies exist, this presentation of acute appendicitis is not widely identified, which might lead to delays in making the right diagnosis and initiating treatment. We herein report a 17-year-old male patient who presented with the clinical manifestations of intestinal obstruction and fever for 3 days. Preoperative ultrasound and subsequent computed tomography were performed. On laparotomy, an obstructed bowel was seen, and the appendix was recognized to be the cause. We herein report a case of intestinal obstruction due to acute appendicitis and present an overview of the literature.

(C) 2020 The Author(s) Published by S. Karger AG, Basel
\end{abstract}

\section{Introduction}

Acute appendicitis is the most common abdominal emergency in both adults and children [1], and has been proven to be a usual cause of small bowel obstruction (SBO) [2]. This condition usually occurs as an effect of adhesion because of periappendicular inflammation [3]. On the other hand, acute appendicitis may rarely present as SBO [4]. The association between 


\section{Case Reports in Gastroenterology}

\begin{tabular}{l|l}
\hline Case Rep Gastroenterol 2020;14:346-353 \\
\hline DOI: 10.1159/000508435 & $\begin{array}{l}\text { @ 2020 The Author(s). Published by S. Karger AG, Basel } \\
\text { www.karger.com/crg }\end{array}$ \\
\hline
\end{tabular}

Hong Duc et al.: Intestinal Obstruction due to Acute Appendicitis

mechanical intestinal obstruction and acute appendicitis was first reported by Hotchkiss in 1901 [5] and Hawkes in 1909 [6]. Since then, individual cases have been reported in the literature, but very few systematic reviews have been found on this subject $[7,8]$. In case of coexistence of the two diseases, the clinical presentation of SBO might predominate the clinical features and hide the usual symptoms of appendicitis [3]. Abdominal imaging has an important role in the diagnosis of acute appendicitis as well as SBO, revealing whether intestinal obstruction occurs, where it is located, how severe the obstruction is, and what its cause is. We herein report a case of acute appendicitis that clinically presented as mechanical SBO.

\section{Case Presentation}

In our case, a 17-year-old male was admitted following 3 days of abdominal pain, nausea, and vomiting. No history of surgery or other medical issues was noted. On clinical examination, there was a high body temperature of $39^{\circ} \mathrm{C}$, abdominal distension, and mild tenderness in the right hypogastric region. Upon routine blood investigations, an increased number of white blood cells $(13.7 \mathrm{G} / \mathrm{L})$ was recorded. For diagnosis, X-ray, ultrasound (US), and computed tomography (CT) were used.

On abdominal X-ray, several typical signs of intestinal obstruction were observed, including distended loops of the small bowel, multiple air-fluid levels in the middle of the abdomen, and air in the cecum. A high-attenuation stone at the sacral foramina of S2 level was noted, suggesting an unusual location of appendicular stercolith (Fig. 1).

US observations showed a dilatation of the small intestine loops with contenant fluid measuring $>30 \mathrm{~mm}$ in diameter, and dysfunctional "to-and-fro" peristalsis of the bowel contents. The presence of an enlarged appendix measuring $16 \mathrm{~mm}$ in diameter, contenant fluid with big appendicolith, and surrounded fat infiltration were also found. No fluid was noted between the intestinal loops and the abdominal cavity (Fig. 2).

Immediately, a CT was assigned to confirm the diagnosis. Clearly, it showed appendicitis with stercolith in the medial iliac vascular and a fluid-filled tip into the pelvis. Further, there was surrounding inflammation adhered to the 4.6-cm dilated small intestinal loops (Fig. 3).

Imaging and surgical procedures were all performed on the same day. Intraoperative images demonstrated appendicitis with necrosis on the tip, which was covered by the small intestinal loops. It was seen to adhere to the small intestinal loops and cause complete obstruction (Fig. 4). Histopathological anatomy confirmed necrotic appendicitis due to stercolith. There were no complications after surgery, and the patient was discharged after few days.

\section{Discussion}

SBO secondary to appendicitis is relatively rare. Recently, Makama et al. [4] reviewed the literature from January 1950 to June 2016, and there were only 27 articles and 45 case reports concerning SBO due to appendicitis, of which up to 25 (92.6\%) of the articles reported on a single case.

Regarding the relationship between appendicitis and SBO, Beltrán [9], in a retrospective study, reviewed a hospital over 15 years (from 1999 to 2013), and produced the following results. Among patients with SBO, appendicitis accounted for $2.7 \%$ of the cases $(44 / 1,628)$. In contrast, among patients who underwent appendicitis surgery, only $1.2 \%$ experienced bowel obstruction $(44 / 3,626)$. This low rate can also be explained by the fact that not all appendicitis 


\section{Case Reports in Gastroenterology}

Case Rep Gastroenterol 2020;14:346-353

DOI: $10.1159 / 000508435$

c) 2020 The Author(s). Published by S. Karger AG, Basel www.karger.com/crg

Hong Duc et al.: Intestinal Obstruction due to Acute Appendicitis

locations, when inflammation occurs, can cause SBO; this is only a risk of appendicitis in the abdomen and peri-ileal hypogastric region, accounting for about $50 \%$ of all cases. The appendicitis wrapping the ileum carries the highest risk for intestinal obstruction, but this position only accounts for $2.4 \%$ of the cases [10]. This means that the ratio of bowel obstruction secondary to appendicitis is $2.7 \%(44 / 1,628)$ [9].

The classification of SBO caused by appendicitis, as well as the ileus, generally consists of three groups: mechanical, adynamic (paralytic ileus), and ischemia (secondary to mesenteric ischemia) [4]. The most common cause is mechanical. With open loop obstruction, we may see the following morphologies: the tip of the inflamed appendix adheres directly to the bowel wall (Fig. 5a); the tip of the inflamed appendix adheres to the posterior peritoneum across the ileum (Fig. 5b) [4]; or the tip of the inflamed appendix adheres to the mesentery near the ileocolic artery (Fig. 5c) [11]. These three forms can all cause intestinal obstruction due to tightening, folding, twisting, pinching, or pulling of the appendicitis [3]. With closed loop obstruction, the inflamed appendix wraps around the last loop of the ileum (Fig. 5d); the inflamed tip of the appendix adheres to the posterior peritoneum or the root of the appendix $[2,12,13]$, or herniation of intestine occurs through a gap formed by the appendix tip being attached to its base [14], and this might lead to necrosis $[7,8,15]$. The mechanism and morphology of bowel obstruction relate to the position, mobility, and length of the appendix; an inflamed appendix might adhere to the other surrounding structures, such as the ileum, the mesentery of the ileum, the caecum, and/or the colon, the posterior peritoneum, or right tubo-ovarian complex $[4,15]$.

Diagnosis of intestinal obstruction is usually based on clinical and X-ray findings, and knowing the precise cause of SBO is necessary to make an early surgical decision. Therefore, additional imaging methods are often indicated for these cases, especially for cases where clinical examination shows abdominal pain mainly on the right side/iliac fossa.

The US may show signs of SBO such as dilated bowel loops, thick intestinal wall with increased "to-and-fro" peristalsis or loss, and fluid between the bowel loops. However, these signs are likely to be missed or difficult to find in early inflammatory appendicitis due to intestinal obstruction. Consequently, US has often not been mentioned in previous studies. In our case, the cause of intestinal obstruction was a typical appendicitis with appendicolith corresponding to the location on X-ray.

In the case of SBO caused by acute appendicitis, CT is an additional examination helpful for diagnosis and prognosis $[12,15]$, with enhancement of the dilated small bowel wall and intra-abdominal fluid. However, the role of CT in detecting appendicitis is also case-by-case; often, it is not found due to the inflamed appendix being wrapped around the ileum [11-13, 15]. It may be seen in enlarged purulent appendicitis [3], as in our case. Thus, CT's ability to diagnose appendicitis is related to the progression of the inflamed appendix.

The final diagnosis of SBO due to appendicitis is completely based on surgery; the best approach to clear this condition is through laparotomy. Depending on the situation of the obstruction, the treatment may be variable, from a simple appendectomy to ileocecal segmental resection, or even to a right-sided hemicolectomy based upon the severity of the appendicitis and the necrosis of the bowel loops [9].

In conclusion, intestinal obstruction by appendicitis is very rare and is associated with the location of the inflamed appendix around the ileum causing open or closed loop obstructions. Appendicitis should be considered one of the potential causes of intestinal obstruction to avoid delays in diagnosis and treatment. In addition to clinical examination and abdomen $\mathrm{X}$-ray, US and especially CT might be necessary for diagnosis. Typical cases are enlarged 


\section{Case Reports in Gastroenterology}

\begin{tabular}{l|l}
\hline Case Rep Gastroenterol 2020;14:346-353 \\
\hline DOI: 10.1159/000508435 & $\begin{array}{l}\text { @ 2020 The Author(s). Published by S. Karger AG, Basel } \\
\text { www.karger.com/crg }\end{array}$ \\
\hline
\end{tabular}

Hong Duc et al.: Intestinal Obstruction due to Acute Appendicitis

purulent appendicitis causing adherence of the intestinal loops. Definitive diagnosis is still achieved with open surgery.

\section{Statement of Ethics}

The Institutional Review Board of Ha Noi Medical University approved this case study. Written informed consent of the patient was obtained.

\section{Conflict of Interest Statement}

The authors declare no financial disclosures or conflicts of interest.

\section{Funding Sources}

There were no funding sources.

\section{Author Contributions}

P.H. Duc and N.M. Xuan contributed equally to this article. P.H. Duc, N.M. Xuan, N.H. Thuyet, and H.Q. Huy made and confirmed the diagnosis, provided the details of the case, and contributed to the design of the report. P.H. Duc, N.M. Xuan, and H.Q. Huy drafted the manuscript. All authors read and approved the final version of the manuscript.

\section{References}

1 Saidi HS, Adwok JA. Acute appendicitis: an overview. East Afr Med J. 2000 Mar;77(3):152-6.

2 Awale L, Joshi BR, Rajbanshi S, Adhikary S. Appendiceal tie syndrome: A very rare complication of a common disease. World J Gastrointest Surg. 2015 Apr;7(4):67-70.

3 Harrison S, Mahawar K, Brown D, Boobis L, Small P. Acute appendicitis presenting as small bowel obstruction: two case reports. Cases J. 2009 Nov;2:9106.

4 Makama JG, Kache SA, Ajah LJ, Ameh EA. Intestinal Obstruction Caused by Appendicitis: A Systematic Review. J West Afr Coll Surg. 2017 Jul-Sep;7(3):94-115.

5 Hotchkiss LW. V. Acute Intestinal Obstruction following Appendicitis. A Report of Three Cases Successfully Operated upon. Ann Surg. 1901 Nov;34(5):660-77.

6 Hawkes F 3rd. III. The Prevention of Intestinal Obstruction Following Operation for Appendicitis. Ann Surg. 1909 Feb;49(2):192-207.

7 Assenza M, Ricci G, Bartolucci P, Modini C. Mechanical small bowel obstruction due to an inflamed appendix wrapping around the last loop of ileum. G Chir. 2005 Jun-Jul;26(6-7):261-6.

8 O'Donnell ME, Sharif MA, O'Kane A, Spence RA. Small bowel obstruction secondary to an appendiceal tourniquet. Ir J Med Sci. 2009 Mar;178(1):101-5.

9 Beltrán MA. Intestinal obstruction in appendicitis: A retrospective cohort study. Hellenic J Surg. 2017;89(2):92-9.

10 de Souza S, da Costa SR, de Souza IG. Vermiform appendix: positions and length-a study of 377 cases and literature review. J Coloproctol (Rio J). 2015;35(4):212-216.

11 Agrawal S, Sachan PK, Pathak P, Chaudhary T, Zaidi R, Narayan S. Appendicitis: a rare cause of intestinal obstruction. Sri Lanka J Surg. 2018;36(1):45-6.

12 Ahmed KA, Hamdy AM, Seifeldin MI, Elkeleny MR. Mechanical small bowel obstruction due to appendiceal tourniquet: a case report and review of literature. J Med Case Reports. 2019 Aug;13(1):208. 


\section{Case Reports in Gastroenterology}

\begin{tabular}{l|l}
\hline Case Rep Gastroenterol 2020;14:346-353 \\
\hline DOI: 10.1159/000508435 & $\begin{array}{l}\text { @ 2020 The Author(s). Published by S. Karger AG, Basel } \\
\text { www.karger.com/crg }\end{array}$ \\
\hline
\end{tabular}

Hong Duc et al.: Intestinal Obstruction due to Acute Appendicitis

13 Maly 0, Paral J. Appendicitis as a rare cause of mechanical small-bowel obstruction: A literature review of case reports. Int J Surg Case Rep. 2016;29:180-184.

14 Lawani I, Houndje CY, Souaïbou YI, Gbéssi DG, Attolou SG, Gnangnon FH, et al. Internal hernia strangulated on appendicular tourniquet: a case report of an exceptional anomaly of the appendix revealed by a rare hernia. Surg Case Rep. 2019 Jul;5(1):112.

15 Bhandari L, Mohandas P. Appendicitis as a cause of intestinal strangulation: a case report and review. World J Emerg Surg. 2009 Oct;4:34.

Pham Hong Duc and Ngo Minh Xuan contributed equally to this article

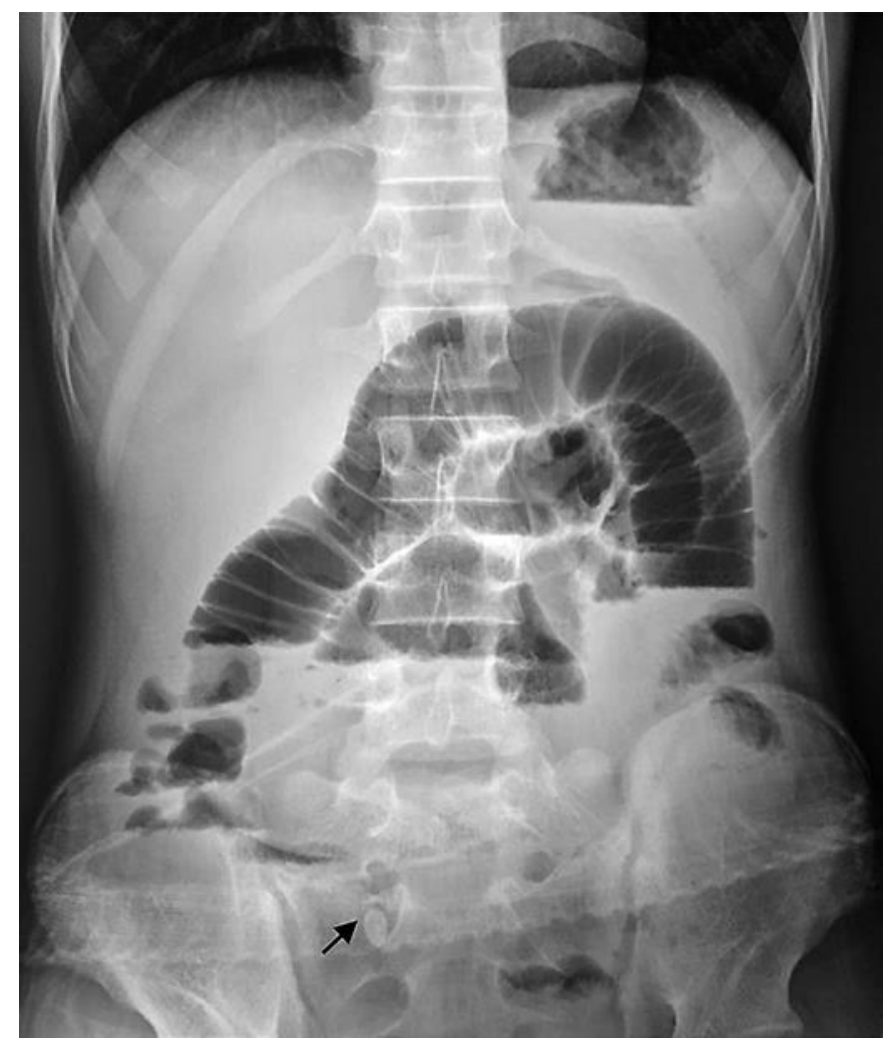

Fig. 1. Abdominal X-ray demonstrating multiple air-fluid levels and distended loops of the small intestine. Pelvis appendicolith (arrow). Note spina bifida occulta s1. 
Case Reports in Gastroenterology
Case Rep Gastroenterol 2020;14:346-353

DOI: $10.1159 / 000508435$

(c) 2020 The Author(s). Published by S. Karger AG, Basel www.karger.com/crg

Hong Duc et al.: Intestinal Obstruction due to Acute Appendicitis

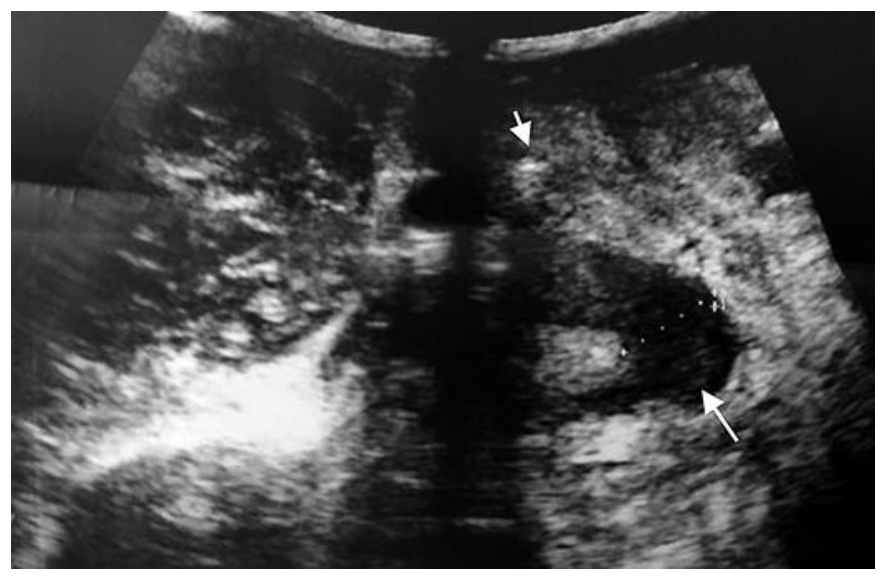

Fig. 2. US of the right hypogastric region. Echogenic of the partial appendicolith (short arrow); the tip of the appendix is dilated, filled with pus in the lumen; wall thickness (long arrow); periappendiceal fat stranding. 


\section{Case Reports in Gastroenterology} www.karger.com/crg

Hong Duc et al.: Intestinal Obstruction due to Acute Appendicitis
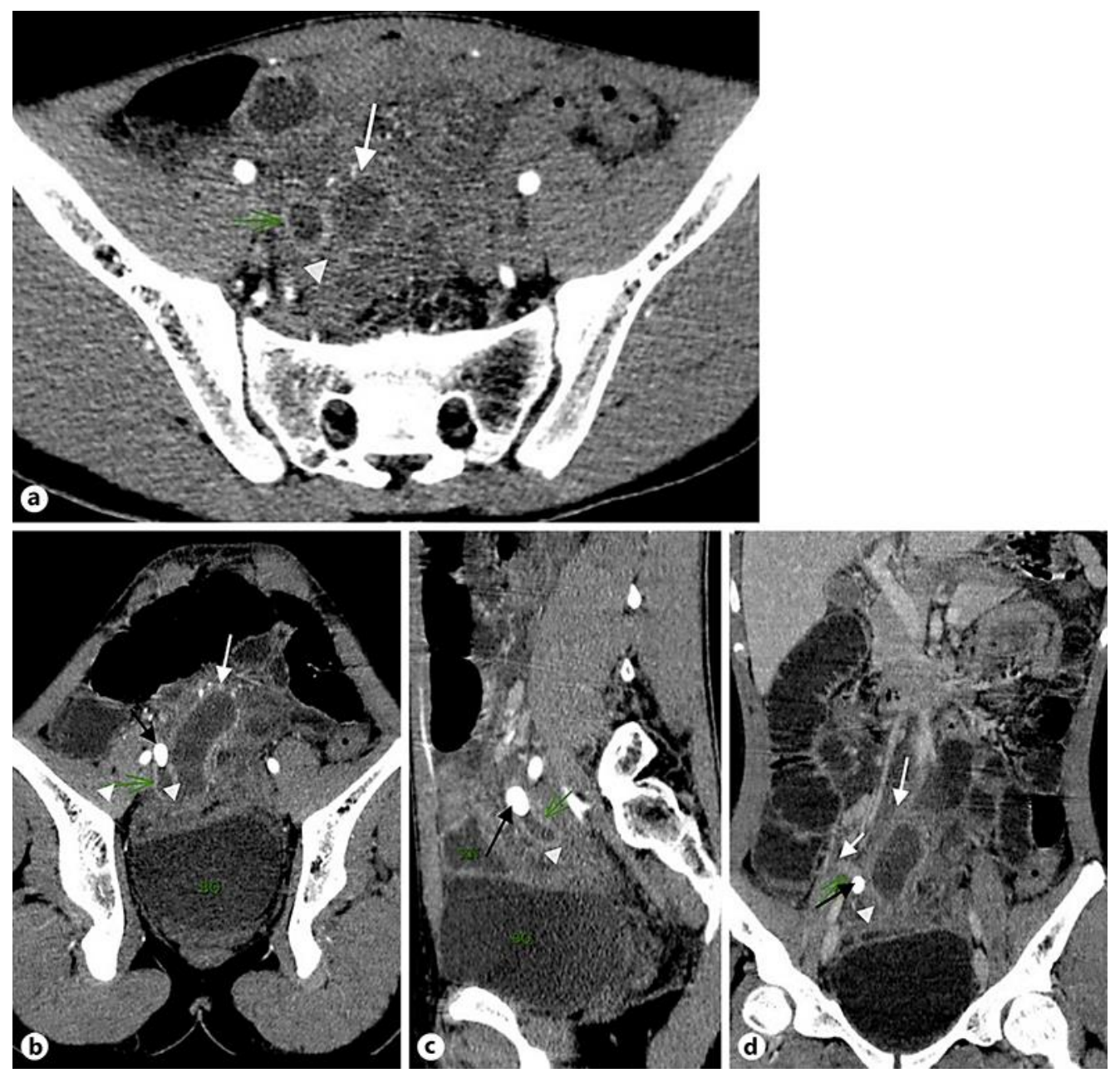

Fig. 3. CT with injected contrast medium. Axial (a), oblique axial (b), sagittal (c), and coronal (d) views. The tip of the inflamed appendix (green arrow) was $16 \mathrm{~mm}$ in size. Enhanced wall; fluid-filled, periappendiceal fat stranding (white arrowhead); small bowel loops are adhered and dilated (white arrow). The proximal part seems normal (short white arrow in $\mathrm{d}$ ); limited to the tip of the appendix by the appendicolith, $16 \mathrm{x}$ $10 \mathrm{~mm}$ in size (black arrow). 
Case Reports in Gastroenterology
Case Rep Gastroenterol 2020;14:346-353

DOI: $10.1159 / 000508435$

(c) 2020 The Author(s). Published by S. Karger AG, Basel www.karger.com/crg

Hong Duc et al.: Intestinal Obstruction due to Acute Appendicitis

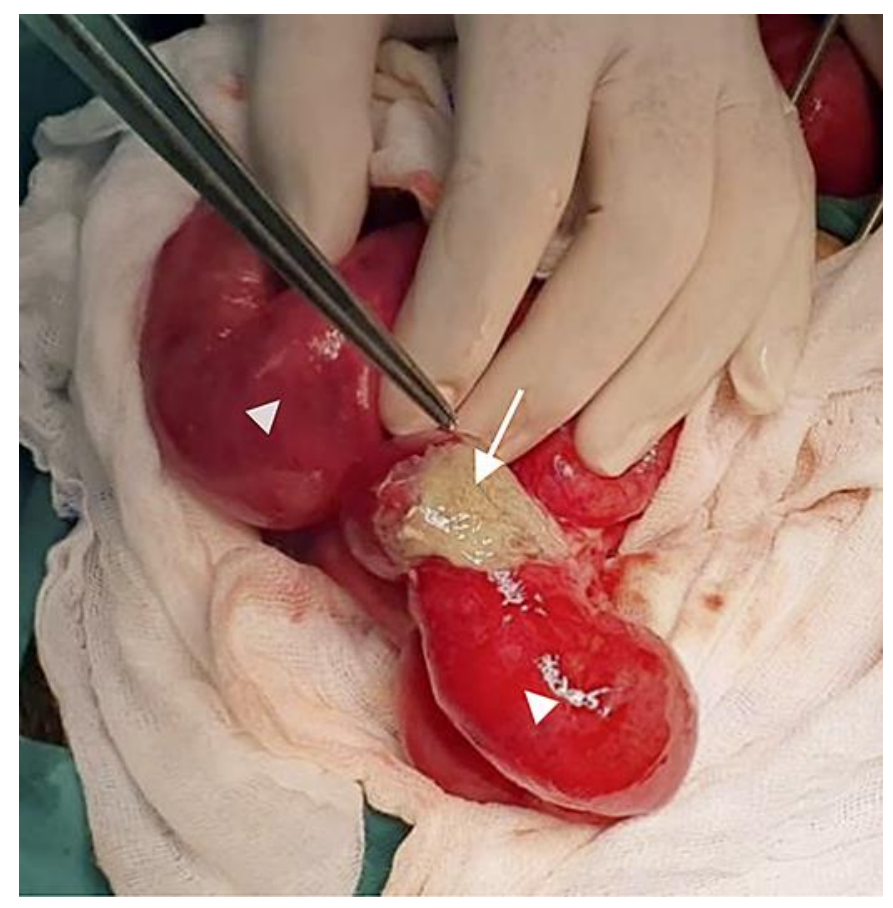

Fig. 4. Intraoperative image. The tip of the inflamed appendix was dilated, and pus spilled out (arrow). The small bowel loops were adhered to the appendix and dilated, with no sign of necrosis (arrowheads).
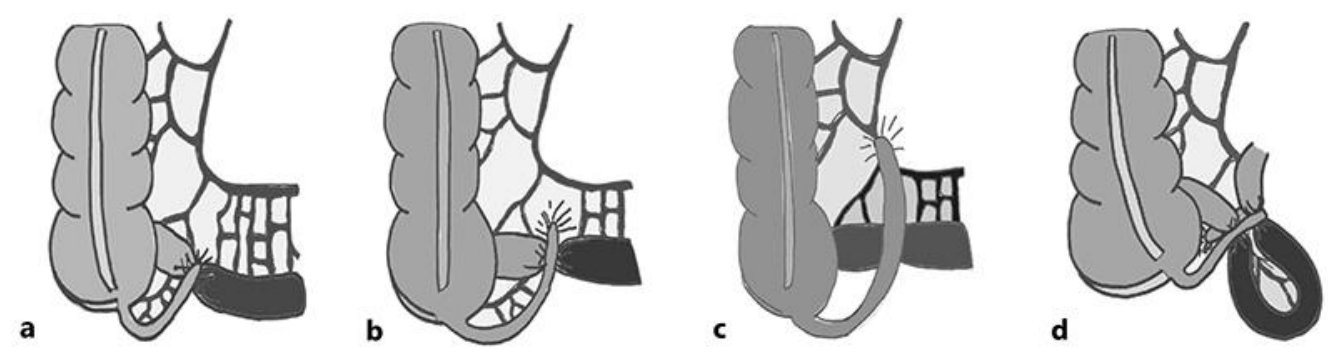

Fig. 5. Mechanical small bowel obstruction due to an inflamed appendix wrapping around the last loop of the ileum. The tip of the inflamed appendix adheres directly to the bowel wall (a); the tip of the inflamed appendix adheres to the posterior peritoneum across the ileum (b); the tip of the inflamed appendix adheres to the mesentery near the ileocolic artery (c), and the inflamed appendix wraps around the last loop of the ileum (d). 